\title{
MULHERES E(M) SILENCIAMENTO: DESNATURALIZANDO SUPRESSÕES DA ESCRITA POÉTICA DE LOLA RIDGE
}

Laura Pinhata Battistam Líliam Cristina Marins

Resumo: O cânone literário tem sido, historicamente, de difícil acesso para as mulheres autoras e apenas há pouco houve a possibilidade desse espaço ser, ainda que minimamente, ocupado por elas. No entanto, esse lugar continua sendo restrito e limitado a certas mulheres enquanto outras ainda são silenciadas. Este artigo visa investigar, a partir das formas do silêncio fundamentadas em Orlandi (1997), as limitações da produção de uma literatura canônica de autoria feminina, tomando como exemplo a obra poética produzida por Lola Ridge, poeta da classe trabalhadora que compõe a literatura proletária entre os anos de 1915 e 1930, nos Estados Unidos. Lola Ridge é uma entre diversas outras poetas mulheres que foram relegadas ao silenciamento e ao esquecimento, em consonância com as críticas feministas Russ (2018), Olsen (2003) e Berke (2001). Buscase, portanto, questionar a condição da mulher no cânone literário e discutir a possibilidade de recuperação dessas obras pela prática da Tradução Feminista.

Palavras-chave: Silenciamento. Cânone literário. Crítica feminista. Literatura proletária.

Abstract: From a historical perspective, the literary canon has been hardly accessible to women authors and only a few years ago there were possibilities of this space become, yet minimally, occupied by them. However, this place is still being restricted and limited to certain women whilst others are being silenced. This paper aims to analyze the limitations of women literary production based on the shapes of silence theorized by Orlandi (1997) and on Lola Ridge's poetic production, an important woman poet from the American workingclass literature over the period of 1915 and 1930 in the United States. Lola Ridge is one among many other women poets who were silenced and forgotten, according to feminist critics as Russ (2018), Olsen (2003) and Berke (2001). Therefore, we seek to question the condition 
of women in the literary canon and to discuss the possibility of recovering these works through the practice of Feminist Translation.

Keywords: Silencing. Literary canon. Feminist criticism. Working-class literature.

\section{INTRODUÇÃO}

É sabido que o cânone literário é um espaço ocupado por uma parcela desproporcional de homens. No século XX, houve pouquíssimas autoras mulheres que conseguiram prestígio canônico, sendo este ainda um número menor se comparado aos escritores do sexo masculino. As justificativas para tal fato, a partir do senso comum, podem passar pela falta de criatividade, pela incapacidade ou pela falsa crença de haver um número menor de mulheres escritoras do que de homens escritores. No entanto, será que as mulheres não escreviam? Caso escrevessem, seriam essas obras literárias insuficientemente boas para receber prestígio? Seriam essas justificativas naturais para o processo de produção da literatura? Questionamentos como esses se tornaram o impulso desta reflexão.

Pesquisadoras feministas se debruçam sobre o tema há alguns anos em busca de respostas para essas perguntas levantadas em relação à condição da mulher no cânone literário. Uma grande parcela de escritores do período moderno da literatura estadunidense conhecida hoje são 
homens. No entanto, de acordo com Berke (2001, p. 2), durante a década de 80 , críticas literárias feministas como Susan Stanford Friedman, Shari Benstock, Carolyn Burke, Sandra M. Gilbert e Susan Gubar pesquisaram sobre gênero no período moderno e recuperaram as obras importantes de mulheres escritoras como Gertrude Stein, Djuna Barnes, H.D. e Mina Loy.

Estudar o cânone literário moderno estadunidense buscando compreender as formas nas quais a escrita de mulheres, como Lola Ridge, foram suprimidas nele, fazse necessário, primeiramente, entender as formas de silenciamento nas quais as mulheres podem ser submetidas. Para tanto, será realizada uma breve teorização sobre as formas do silêncio, de acordo com Orlandi (1997), e as formas de suprimir a escrita de mulheres dentro das categorias analíticas propostas por Russ (2018), em consonância com a crítica feminista e materialista de Olsen (2003). Como o foco deste trabalho será na poesia produzida no período moderno da literatura estadunidense, especialmente da literatura proletária, a poeta aqui citada será entendida como exemplo de escritora cuja obra foi silenciada ao longo do tempo. Na terceira parte do artigo, Lola Ridge e sua obra serão contextualizadas e analisadas pelas categorias elencadas por Russ (2018). 
Segundo Russ, em uma sociedade igualitária, a situação ideal seria aquela na qual os membros desse grupo "errado" - isto é, mulheres, camponeses, trabalhadores em geral tivessem a liberdade de se engajar na produção literária e "ainda assim, não o fazer, provando então que são incapazes" (RUSS, 2018, p. 4, tradução nossa), todavia, os membros desse grupo considerado "inadequado", principalmente as mulheres, escreveram - e continuam escrevendo. Dessa maneira, a justificativa mais comum para o fato de existir um pequeno número de mulheres canônicas (a de que as mulheres não possuem habilidades para produzir uma literatura qualificada) é negada. Essa justificativa é completamente reducionista por não compreender as complexidades envolvidas nessa supressão.

Mesmo que tenha havido mulheres que tiveram uma educação formal e publicaram obras literárias, existe inúmeras críticas que insistem em desvalorizar e/ou diminuir o trabalho delas e, quando estas críticas as elogiam, as comparam com escritores homens já consagrados previamente. Pensando sobre a desigualdade no prestígio literário entre homens e mulheres escritoras, Russ (2018) buscou encontrar um padrão analítico para categorizar as estratégias desse silenciamento. As estratégias elencadas 
por Russ (2018) - onze, no total - circundam dentro dos seguintes pontos: proibições informais, negação da autoria em questão, desvalorização e isolamento do trabalho, anomalia das mulheres autoras, afirmações de má-fé sobre a autoria ou, simplesmente, o desconhecimento do trabalho, das escritoras e de toda a tradição deste grupo de mulheres, sendo essa última a mais comum e difícil estratégia supressiva de se combater, pois se não há publicações ou registro das obras dessas mulheres no mercado editorial atual, não há como as autoras tornarem-se reconhecidas.

A partir dessas estratégias analíticas, que existem também dentro das formas de silenciamento propostas por Orlandi (1997), surge a necessidade de encontrar padrões na supressão das obras poéticas como as de Lola Ridge, poeta engajada do período moderno da literatura proletária dos Estados Unidos, tomada como exemplo de mulher autora silenciada neste trabalho. Para tanto, primeiramente, fazse necessário a teorização já mencionada das formas do silêncio de Orlandi (1997) e das estratégias de supressão de Russ (2018) para, depois, aplicá-las à obra de Ridge. A importância de compreender esses mecanismos do silenciamento dentro da literatura e do cânone é recuperar, além de denunciar e combater essas práticas que ainda 
se fazem presentes, essas obras que foram relegadas ao esquecimento e ao desconhecimento canônico e social.

\section{UMA BREVE TEORIZAÇÃO SOBRE O(S) SILÊNCIO(S)}

De acordo com Orlandi (1997, p. 44), a linguagem é a categorização do silêncio. Dentro dessa perspectiva, a autora analisa, sobretudo, duas formas: o silêncio fundante e as políticas do silêncio, isto é, o silenciamento. A fim de compreendê-lo por uma perspectiva discursiva, Orlandi (1997, p. 45) afirma que o silêncio não é ausência, não é o vazio. Ele significa em si e, com isso, além de haver vários tipos de significações, há também vários tipos de silêncio, por exemplo, silêncio das emoções, da introspecção, da contemplação, da revolta, da resistência, da disciplina e, o mais importante para este trabalho, o do exercício de poder. Deste modo, pensar o silêncio a partir de uma perspectiva discursiva, é pensá-lo de uma forma não-negativa. A primeira forma deste é chamada de silêncio fundante, o qual "indica que todo processo de significação traz uma relação necessária ao silêncio", enquanto a sua segunda forma, o silenciamento, diz que "ao dizer, ele [o sujeito] estará, necessariamente, não dizendo 'outros' sentidos. Isto produz um recorte necessário no sentido. Dizer e silenciar andam juntos" (ORLANDI, 1997, p. 55). Como o foco deste artigo 
é compreender o silenciamento, este será o aspecto mais explicitado no texto.

Conforme mencionado anteriormente, a principal diferença entre o silêncio fundante e o silenciamento é que o segundo produz um recorte entre o dito e o não-dito, enquanto o primeiro significa por si mesmo. Portanto, ao dizer algo, apagamos, necessariamente, outros sentidos possíveis. O silenciamento torna-se, então, uma política de sentido que pode dividir-se em dois pontos: como silêncio constitutivo e como silêncio local. O primeiro, silêncio constitutivo, representa a política do silêncio antiimplícito, segundo a qual se diz "a" para não deixar dizer "b", este, então, possui um caráter de silêncio fundador, pois, ao mesmo tempo que pertence à própria ordem de produção de sentido, também preside qualquer produção da linguagem. O segundo, silêncio local, é a interdição do dizer. De acordo com Orlandi, uma das manifestações visíveis do silêncio local é a censura que "pode ser compreendida como a interdição da inscrição do sujeito em formações discursivas determinadas" (1997, p. 78), e, como consequência, afeta imediatamente a identidade do sujeito, pois este é afetado pelo - e afeta - discurso. Em suma, as políticas do silêncio estão fundadas no discurso como ferramenta de poder. $\mathrm{O}$ 
"poder-dizer" impõe o silêncio, contudo, este significa em si, por isso, é necessário estudá-lo.

Partindo do pressuposto de que o discurso é, também, uma ferramenta de poder, questiona-se sobre os silenciamentos dentro da própria literatura: quem são as pessoas que podem dizer, ou melhor, escrever? Essa interdição do dizer é uma proibição absoluta? O que pressupõe o silêncio das mulheres na escrita? A fim de buscar respostas sobre os silêncios das mulheres na literatura e no cânone literário, Olsen (2003) tenta compreender os processos de escrita como trabalho para desnaturalizar e desmitificar, isto é, analisar materialmente o ato de escrever para evidenciar que o silenciamento das mulheres como autoras, concordando também com Orlandi (1997), é político.

No movimento de pensar a escrita como trabalho, Olsen (2003) lança luz sobre a materialidade da vida das mulheres consideradas canônicas, especialmente na literatura produzida na língua inglesa. Com isso, a partir de uma crítica feminista materialista, Olsen (2003, p. 16) analisa o perfil da vida dessas mulheres. No último século, a maioria das mulheres que conseguiram o prestígio literário não eram casadas, como Jane Austen, Emily Brontë, Emily Dickinson, 
Louisa May Alcott, ou casaram-se depois de seus trinta anos, como Charlotte Brontë. Além disso, de acordo com Olsen, todas elas pagavam outras mulheres para realizarem os serviços domésticos (2003, p. 17).

A importância de analisar as condições de produção literária como trabalho está no combate da justificativa, geralmente presente no senso comum, de que as mulheres não possuem a capacidade de criar arte. Se ambos, mulheres e homens, são igualmente capazes de criar, por que, em sua maioria, as mulheres se mantiveram fora da esfera prestigiada de escritores? O fato é que o trabalho doméstico e o trabalho do cuidado, isto é, cuidar de filhos, maridos, pais idosos e entre outros, têm sido, histórica e majoritariamente, um trabalho de mulheres. Sendo assim, em concordância com Olsen (2003), as circunstâncias e as condições para a produção da arte para homens e mulheres eram (e ainda são) desproporcionalmente desiguais, revelando que a justificativa de que as mulheres não possuem nem instrumentos, nem capacidade criativa para criar uma boa literatura é reducionista e não abrange as complexidades do processo.

De que forma, então, mulheres da classe trabalhadora ou as mulheres que não pagavam por trabalho doméstico, que 
tinham filhos ou que eram casadas lidavam com o trabalho da escrita? Muitas delas não lidavam, não por incapacidade, mas por não possuírem condições materiais para produzir literatura. No entanto, dentro desse grupo de mulheres que supostamente não deveriam escrever, existiram mulheres que escreviam sobre suas condições como forma de protesto, mas para onde foi essa literatura? De que maneiras foi (e ainda é) possível suprimir a escrita dessas mulheres?

Sobre isso, a fim de compreender a supressão da escrita e a exclusão das mulheres do cânone literário, Russ (2018) encontra padrões que são transformados em categorias analíticas neste silenciamento literário. No total, são onze as categorias elencadas, sendo elas: 1. Proibição; 2. Máfé; 3. Negação da agência; 4. "Poluição" da agência; 5. Desvalorização do conteúdo; 6. Falsa categorização; 7. Isolamento; 8. Anomalia; 9. Falta de modelos; 10. Resposta das autoras; por fim, 11. Normas estéticas.

Embora não haja uma proibição explícita e absoluta que impeça as mulheres de escrever, o que pode ser observado ao longo da história é o difícil acesso das mulheres à educação formal. Dificilmente se espera uma ótima literatura produzida por analfabetas, ou semianalfabetas (embora tenhamos Carolina Maria de Jesus, inestimável 
escritora brasileira), portanto, não é à toa que esse status quo se manteve durante séculos. Segundo Russ (2018), na proibição, primeira categoria analítica, não está só a privação do acesso à educação, mas também a pobreza e falta de lazer certamente são grandes obstáculos para a arte: "a maioria dos trabalhadores das fábricas britânicas no século XIX, enfrentando uma jornada de 14 horas, provavelmente não perderiam uma vida aperfeiçoando rigorosamente um soneto" (RUSS, 2018, p. 6, tradução nossa). Portanto, a literatura produzida por essa classe e, principalmente, por mulheres dessa classe pode servir de grande exemplo para entender padrões nas políticas do silêncio propostas por Orlandi (1997) acerca do silêncio local.

Dentro das proibições não-explícitas, além do acesso à educação e do tempo que deve ser dedicado à arte da escrita, é fundamental também ter acesso aos materiais necessários, como os calhamaços de papel, para praticar essa atividade. As mulheres que conseguiam dedicar tempo e praticar a escrita, em sua maioria, eram desencorajadas. Por exemplo, “Leslie Stephen, pai de Virginia Woolf, em 1881, escreveu para Georgie Eliot que ela tinha 'uma certa incapacidade feminina para criar heróis masculinos'" (RUSS, 2018, p. 12, tradução nossa). O desencorajamento influencia de diversas 
maneiras, seja por meio de julgamentos (como o da escrita inferior), seja a não crença sobre a capacidade feminina, ou até mesmo um ato violento quando se obriga que a mulher seja perfeita o tempo todo, enquanto essa perfeição não é cobrada dos homens na mesma intensidade. No caso de Sylvia Plath, por exemplo, perseguir a tarefa de ser perfeita como mulher e como poeta a fez encontrar a perfeição no suicídio aos trinta e um anos de idade. Entretanto, de acordo com Russ (2018), caso essas proibições não-absolutas falhem, é possível desvalorizar e desconsiderar a arte das mulheres por meio da má-fé.

A má-fé, a segunda categoria elencada por Russ (2018), pode ser traduzida como as estratégias usadas para fazer com que a obra dessas mulheres desapareça ou seja desvalorizada, de alguma maneira, pela sua forma de escrita ou pelo simples fato de ser de uma autora mulher. Já a terceira categoria, a negação da agência, estuda a problemática do que fazer quando uma mulher escreve. A primeira linha de defesa é argumentar a falta da agência da mulher: "ela não escreveu, ele que o fez" ou "o livro se escreveu sozinho". Já que dizer "o livro se escreveu sozinho" parece muito falso e cômico, mesmo como metáfora, "os críticos inventaram uma versão mais sutil que parece restaurar a agência da mulher 
ao mesmo tempo que implica que um 'homem' tenha escrito: o homem dentro dela que escreveu" (RUSS, 2018, p. 22, tradução nossa, grifo da autora). Desta maneira, as mulheres passam a ser comparadas com autores para ganhar alguma credibilidade no mercado e na literatura.

Caso a negação não funcione, o interessante é macular, manchar, poluir a agência dessa autora como em "foi ela que escreveu, mas ela deveria ter escrito isso?", assim, surge a quarta categoria de supressão: a poluição da agência. Geralmente, os argumentos usados circundam a justificativa da escrita de mulheres refletir o caráter e/ou sua decência. Nenhuma mulher virtuosa poderia escrever bem, pois ela estaria ocupada cuidado do lar e dos filhos, sendo assim, a escrita pode revelar uma autora neurótica, anormal, indecente.

A quinta categoria se encontra como a desvalorização do conteúdo, pois já que homens, mulheres, negros/as e brancos/as possuem experiências diferentes, é inevitável que essas experiências estejam refletidas em suas escritas. Desse modo, pertencem a essa categoria as obras que são julgadas como reflexões sobre experiências menos relevantes, supondo que haja uma rotulação hierárquica de experiências mais importantes e relevantes e outras que não importam ou não despertam interesse. 
Já a falsa categorização consiste em, ao invés de considerar uma mulher a autora ou uma escritora, desvalorizar o gênero escrito, ou ainda, categorizar a escritora como regionalista, pois o termo abrange uma concepção de limitação, seja pelos limites da geografia ou do conteúdo. Há outras maneiras que as mulheres também são falsamente categorizadas, mas todas elas partem da afirmação "ela não é ela mesma [uma artista] e não é realmente isso tudo [sério, do gênero certo, esteticamente bom, importante etc.] então, como que 'ela' escreveu?" (RUSS, 2018, p. 61, tradução nossa, grifo da autora). Porém, algumas críticas admitem e permitem que a autora entre para o cânone dos bons e sérios escritores, como ocorreu com as irmãs Brontë, Virginia Woolf, Emily Dickinson e entre outras.

Embora existam escritoras canônicas, Russ (2018) chama a atenção para a sétima categoria analítica ou, da maneira como ela denominou, o "mito da conquista isolada" (RUSS, 2018 , p. 62, tradução nossa). A problemática dessa categoria está relacionada ao fato de que, quando uma mulher consegue alcançar prestígio literário e/ou quando uma obra de fato entra para o cânone dos bons e sérios escritores, essa obra passa a ser um caso isolado e, geralmente, toda 
a produção publicada anteriormente ou posteriormente a essa obra acaba sendo desvalorizada e, em muitos casos, até mesmo esquecida.

Como exemplo claro dessa categoria, há o caso de Mary Shelley, conhecida como a autora de Frankenstein e cuja obra The Last Man "havia apenas uma edição impressa nos Estados Unidos, sendo esta uma edição relativamente cara feita pela editora de uma universidade" (RUSS, 2018, p. 63, tradução nossa), enquanto, ao mesmo tempo, havia quatro edições diferentes de Frankenstein circulando pelo país. Ainda poderia ser citado o caso de Charlotte Brontë, cujos poemas e outros romances foram completamente ignorados, fazendo com que esta se tornasse uma autora de um romance só: Jane Eyre.

Embora os homens também possam ser famosos por apenas uma obra específica, as mulheres são ainda mais atingidas, porque, mesmo sendo famosas escritoras, fazem parte (quando fazem) de poucas antologias e estão presentes em uma pequena parcela de lista de leitura para disciplinas, para aulas ou cursos. Além disso, geralmente a escolha dessas obras prestigiadas reforçam os estereótipos sobre o que uma mulher é capaz de escrever ou sobre o que ela deveria escrever: 
Se uma mulher escritora se apresenta como uma voz pública e política, apague esse aspecto de seu trabalho e enfatize seus poemas de amor, considerados escritos para o seu marido (sem evidência nenhuma) Elizabeth Barret Browning.

Se uma mulher é franca sobre a heterossexualidade, apague qualquer trabalho dela que represente a inadequação masculina ou o seu julgamento independente de homens - Aphra Behn.

Se uma mulher escreve poesia sobre amor homossexual, suprima-a e declare-a uma solteirona infeliz - Amy Lowell.

Se ainda tiver problemas, invente um caso heterossexual (infeliz) para explicar os poemas dela - Emily Dickinson. (RUSS, 2018, p. 65 , tradução nossa)

Essas escritoras não são acidentalmente analisadas pelas suas vidas amorosas ou têm as suas obras classificadas como confessionais ou histéricas, como o caso de Sylvia Plath. Tais caracterizações e estratégias usadas para desvalorizar ou até mesmo valorizar (mas apenas até certo ponto) partem de uma perspectiva e de uma cultura machista dentro da própria arte, que causa a invisibilização e o silenciamento das obras literárias escritas por mulheres. A partir disso, forma-se a oitava categoria: a anomalia.

Esse silenciamento e a desvalorização das obras de mulheres contribuem para que outras obras escritas por outras mulheres caiam no esquecimento, construindo a 
justificativa de "ela escreveu, mas havia poucas mulheres como ela" (RUSS, 2018, p. 76, tradução nossa). Essa forte crença de que as mulheres que conseguiram alcançar o prestígio literário ou conquistaram um espaço no cânone são únicas contribui para suprimir a escrita de outras que estão por vir. Essa caracterização falaciosa de autoras como mulheres incomuns, fenomenais e extraordinárias fazem com que uma mulher "comum" não acredite em seu próprio potencial de escrita, pois esta não se considera uma "exceção à regra".

A estratégia de valorizar a obra de certa autora desconsidera a existência de uma rede de mulheres com as mesmas características durante determinado período, como se existisse apenas uma única autora de qualidade. Essa categoria está diretamente ligada à próxima, que é a falta de modelos, ou seja, se a escrita de mulheres consideradas "comuns" não é publicada, existem poucos modelos de autoras que incentivem que mais e mais mulheres escrevam. Para além disso, como já mencionado, existe uma predominância de autores homens em qualquer programa de disciplinas de graduação ou pós-graduação e, de acordo com Russ (2018, p. 94), até o século XX não havia obra reunindo poesias de mulheres em língua inglesa. Quais são 
os efeitos desse silenciamento para as mulheres que pensam em publicar?

Para responder a esse questionamento, é necessário olhar para a décima categoria: a resposta das mulheres para com essas estratégias. Dentre as respostas, existem três principais: ou essas mulheres cedem e renunciam o trabalho da escrita, isto é, elas deixam de publicar, escreverem apenas gêneros de menor prestígio, ou ainda publicam em veículos desprestigiados. A segunda reação é negar que "mulheres não sabem escrever", utilizando-se de justificativas como "não sou uma mulher" ou "sou mais que uma mulher", como fazia Simone Weil. A última resposta seria a recategorização: mulheres podem escrever, pois enxergam verdades e vivenciam experiências diferentes dos homens.

Para finalizar as categorizações, Russ (2018) discute sobre as normas estéticas da arte. A partir dessas normas, a autora postula questionamentos sobre os padrões analíticos que são centralizados em uma única perspectiva estética a fim de descentralizá-los: “Por que a 'grandeza' na arte é frequentemente agressiva? Por que uma 'boa' literatura precisa ser tão longa? O 'regionalismo' é só mais uma maneira de diminuir o vernacular?" (RUSS, 2018, p. 119, tradução 
nossa). O objetivo desses questionamentos é advogar para a necessidade de criticar uma obra a partir da multiplicidade de estéticas e não apenas uma, canônica, que não abrange a literatura periférica ou, no caso deste artigo, a proletária.

Em suma, é a partir das políticas do silêncio teorizadas por Orlandi (1997), especialmente do silêncio local, que a maioria das obras de escritoras mulheres, quando eram publicadas, passaram (e ainda passam) por diversas tentativas de supressão de modo geral. No entanto, o que acontece com obras consideradas "subversivas" e políticas, como as de Lola Ridge e outras poetas da literatura proletária estadunidense produzida entre os anos de 1915 e 1930? O trabalho de recuperação dessas obras tem sido feito por muitas pesquisadoras feministas com a finalidade de mostrar que havia diversas mulheres da classe trabalhadora produzindo literatura de qualidade, mesmo sem as condições de produção ideais.

\section{SILENCIAMENTO E SUPRESSÃO: O EXEMPLO DE LOLA RIDGE}

Antes da breve análise da supressão da escrita de Lola Ridge, é importante contextualizar sobre suas produções. De acordo com Berke (2001, p. 10), o período moderno da literatura estadunidense, aproximadamente entre 1915 e 1945, tem sido o objeto de estudo de diversas pesquisas 
a partir de críticas feministas, dado o grande número de mulheres que participaram do movimento modernista estadunidense como artistas, editoras, escritoras, poetas, entre outras. Porém, a maioria das pesquisas realizadas acerca desse período era sobre a produção literária masculina.

Como já citado na introdução deste artigo, durante a década de 80 , pesquisadoras feministas desafiaram os estereótipos e investigaram diversas produções literárias de mulheres do período moderno, dentre as quais serão focalizadas apenas as obras poéticas, mesmo que tenha havido romances e outras produções. No entanto, uma grande parcela dessas antologias poéticas feministas recuperadas precisavam ser "esteticamente" - recuperando a décima primeira categoria de Russ (2018) - aceitáveis para a grande literatura, sendo publicadas apenas antologias de escritoras "apolíticas" ou neutras, como a The World Split Open: Four Centuries of Woman Poets in England and in America, 1552 - 1950, compilada por Louise Bernikow e publicada em 1974 pela editora Random House Inc. Devido a esse fato, geralmente, as poetas consideradas engajadas politicamente ou radicais tendiam a ser ignoradas e não publicadas. Segundo Berke (2001), como resultado disso, uma tradição de mulheres poetas estadunidenses que 
escreviam poesia socialmente engajada sofreram quase uma negligência.

Embora Lola Ridge não estivesse sozinha na produção de poemas de protesto contra a repressão social e política nos Estados Unidos, ela é um dos exemplos de poetas mulheres representantes de discurso poético negligenciado. A poesia social, principalmente de cunho ideológico, como é o caso de Ridge, tem sido historicamente marginalizada por "histórias literárias que ou classificam o poema como objeto popularizado pelo New Criticism ou como desinteresse abstrato encontrado nas tradições de poetas canônicos como T. S. Eliot e Marianne Moore" (BERKE, 2001, p. 6, tradução nossa, grifo da autora). Foram nos espaços sociais alternativos aos mencionados anteriormente que poetas como Ridge criaram seu trabalho, uma poesia que não era puramente baseada em valores estéticos.

Mesmo que Ridge tivesse interesse nos aspectos formais dos poemas, ela se preocupava mais em como os poemas poderiam "representar o sofrimento e a luta humana para leitores diversos" (BERKE, 2001, p. 6, tradução nossa). Seus poemas eram sobre suas observações sociais e representavam alguns dos momentos históricos específicos da formação social estadunidense, como a escravidão e a 
exploração da classe trabalhadora, fazendo o uso de uma linguagem moderna e não-erudita para que leitores comuns a ela se aproximassem e se reconhecessem no poema. Enfatizar o compromisso social e a consciência política era, para ela, a matéria-prima do poema, mas não o único objetivo deste. Uma grande parcela das críticas entendia a poesia engajada como propaganda política, sendo assim, poucos críticos estudavam a sua estética, forma e conteúdo como produção de cultura. Algumas dessas obras não eram nem consideradas de valor poético. Estudar poetas como Ridge lança um desafio sobre a crítica feminista, pois sugere que poetas não-canônicas também representam o modernismo estadunidense.

De acordo com Berke (2001), as críticas do período pós-guerra, principalmente dos New Critics, contribuíram para o silenciamento de mulheres artistas, pois estas eram embasadas por um viés anti-histórico e antissociológico. Segundo as críticas, o "poder" e a "ardência" das autoras construíram uma estética socialmente consciente. Por meio de suas poesias, Ridge e diversas outras poetas, como Genevieve Taggard e Sarah Cleghorn, estabeleceram o que Berke chama de poesia da práxis, pois o trabalho delas demonstra "a ideia altamente contestada de que a poesia 
pode ser usada tanto para abordar problemas sociais, quanto como registro para a posteridade histórica da cultura social e política de seu tempo" (BERKE, 2001, p. 7, tradução nossa). A maioria do trabalho de Ridge foi publicada em revistas de cunho político relacionadas à esquerda, como a New Masses.

É importante lembrar que o silenciamento, especificamente o silêncio local, nos termos de Orlandi (1997), e a supressão da escrita dessas poetas pelas categorias de Russ (2018) citadas anteriormente não foi um processo natural e apolítico. Falar de poesia engajada, sendo este um gênero desprestigiado, e de um conteúdo considerado "arriscado" para aquela sociedade, produzido por um grupo mulheres exploradas em um país como os Estados Unidos, é como contar uma história silenciada sobre uma história silenciada.

Lola Ridge nasceu em Dublin, em 1873, e cresceu na Austrália e na Nova Zelândia. Ela se mudou para os Estados Unidos em 1907, estabelecendo-se no Greenwich Village em Nova York em 1908 e tornou-se ativa no movimento anarquista. Segundo Berke (2001), Ridge trabalhou como organizadora para a Ferrer Association, associação de trabalhadores que seguiam as ideias de Francisco Ferrer, um catalão que foi executado por advogar a favor das 
reformas na Educação, pois ele acreditava na educação libertadora e emancipatória.

Ridge ajudou a fundar a revista Modern School da Ferrer Association e foi durante esses anos de atividade política que ela desenvolveu a sua carreira como poeta modernista. Sua carreira como literária foi breve, e Ridge tinha consciência de que nenhuma boa literatura nascia de dogmas, porém, como poeta, entendia o conflito entre a prática estética e a vida social que a formava enquanto arte. Suas duas identidades, como poeta e como ativista política, afetaram sua obra completamente.

Nenhum dos cinco livros que Ridge publicou é comercializado ou impresso atualmente. Seu primeiro livro, The Ghetto and Other Poems, foi publicado em 1918, quando ela tinha 45 anos de idade. Essa coletânea de poemas trabalhava criticamente com os temas de imigração e trabalho e obteve certo sucesso crítico. Sunup, seu segundo livro, foi publicado em 1920, e ambas as coletâneas saíram por uma editora independente fundada por B. W. Huebsch. Seus outros títulos publicados são Red Flag (1927), cujo tema celebrava a Revolução Russa, Firehead (1929), o qual utilizou a crucificação de Cristo como uma alegoria para a execução dos anarquistas 
italianos Nicola Sacco e Bartolomeo Vanzetti e, por último, Dance of Fire (1935). De acordo com Berke (2001), Ridge passou os últimos anos de sua vida com invalidez e morreu de tuberculose em maio de 1941, com sessenta e seis anos.

A carreira literária de Lola Ridge, promovida por uma editora independente e por suas publicações em revistas políticas, gerou conexões com outros autores da época durante os anos 1920. No entanto, "nenhum desses artistas [Marianne Moore, Aaron Copeland e Paul Strand] teria imaginado que quando Ridge morresse, seus poemas seriam enterrados com ela." (BERKE, 2001, p. 33, tradução nossa). Para estudar a obra de Lola Ridge é necessário atentar-se para a consciência da poeta de fazer arte nascer de suas convicções políticas, pois ela instrumentalizava a sua arte como forma de resistência, e pouquíssimos de seus poemas podem ser classificados como pessoais. Ridge era uma defensora da liberdade individual, participando do movimento para o direito das mulheres, dos trabalhadores, dos negros, dos judeus e de outros grupos minoritários de imigrantes.

É a partir das escassas críticas sobre seus poemas que pode ser observado duas das categorias supressivas elencadas por Russ (2018) - má-fé e a poluição da agência, 
pois ela era considerada "uma mulher frágil e doentia, mas que tinha paixão intensa e zelo revolucionário" (BERKE, 2001, p. 34, tradução nossa). Ridge era uma poeta que produzia na contracorrente da tradição das mulheres canônicas de enfatizar a vida privada e a vida a dois. Esse conflito entre a vida pública e a vida privada e o fato de colocar o seu engajamento político subjetivo em sua obra, na época em que o dogma da poesia modernista estava "não nas ideias, mas nas coisas" (BERKE, 2001, p. 34, tradução nossa), foi desafiador para seu trabalho, cuja leitura envolvia o corpo social não "permitido" nas normas estéticas. Portanto, Ridge era vista como uma poeta secundária, porque não se encaixava na escrita mainstream de mulheres canônicas.

Entre as onze categorias analíticas propostas por Russ (2018) anteriormente mencionadas, é possível notar que, em pelo menos cinco delas, a escrita de Lola Ridge sofreu supressão. Como não é o objetivo deste trabalho analisar os poemas de Ridge, mas sim a sua produção literária como um todo para propor uma compreensão sobre o silenciamento e a exclusão da poeta do cânone literário, serão descritas a seguir as tentativas de supressão analisadas à luz das categorias de Russ (2018) e no silêncio local proposto por Orlandi (1997). 
É interessante pensar o silêncio local na obra de Ridge como uma tentativa de interdição do dizer das vozes sociais promovidas pelo corpo social do conteúdo de seus poemas. Dito isso, a categoria da proibição pode ser observada em dois aspectos principais relacionados à obra da poeta: o primeiro deles é o fato de Ridge não ter sido publicada por grandes editoras, mas por uma pequena editora independente, fazendo com que sua obra tivesse pequena circulação. Conforme já mencionado, a proibição - enquanto categoria analítica - pode ser entendida de diversas formas, no entanto, em sua maioria, não são proibições absolutas. O segundo aspecto da proibição na obra de Ridge é o desencorajamento da escrita, isto é, o julgamento pelo conteúdo de seus poemas e a sua desobediência em relação às normas estéticas que contribuíram para que Ridge fosse pouco lida e, consequentemente, pouco criticada.

Em segundo lugar, podemos observar a categoria da má-fé, cuja tentativa de fazer com que a obra já publicada sumisse (caso as proibições não funcionassem primeiro), foi bem-sucedida. Após a morte de Ridge, toda a sua obra ficou relegada ao esquecimento e, até os dias atuais, não existe nenhum projeto de reimpressão ou de comercialização de seus poemas. Apesar de The Ghetto and Other Poems, por exemplo, se encontrar 
disponível em domínio público, há pouquíssimo conhecimento de seu nome enquanto poeta atualmente.

A terceira categoria observada na supressão da escrita engajada de Ridge é a poluição da agência. Apesar de ter sido pouco lida e pouco criticada, as parcas críticas relacionadas à obra de Ridge afirmavam, como já mencionado, que ela era uma mulher "doentia" e "frágil". A maculação da imagem da poeta resulta em um desencorajamento referência à categoria da proibição, pois são estratégias interconectadas -, em termos psicológicos, de continuar a escrever e publicar. Esse desencorajamento está conectado com as duas últimas categorias que podem ser analisadas no silenciamento da poeta: a desvalorização do conteúdo (e do gênero) e as normas estéticas.

Se uma mulher escreve sobre sua vida privada, ela tem sua escrita considerada confessional, pessoal e irrelevante, se uma mulher escreve sobre as violências cotidianas do povo, como é o caso de Ridge, ela deveria, de acordo com a crítica, voltar a falar apenas sobre as suas experiências privadas. Ironicamente, Ridge não só falava de suas experiências pessoais, mas das experiências de toda uma classe de trabalhadoras, mulheres, negras e imigrantes que se sentiam representadas por sua escrita. Em suma, o fato de Ridge 
dedicar toda a sua breve carreira literária à poesia da práxis fez com que ela nunca tenha produzido nenhuma poesia que se era esperada de uma mulher. Como suas preocupações estéticas estavam mais relacionadas à acessibilidade da linguagem, ela não possuía nenhuma característica que pudesse torná-la canônica.

Devido à essa exclusão do cânone que os trabalhos das pesquisadoras feministas, como Berke (2001), têm sido importantes para recuperar tais obras a fim de que se estabeleça novos modelos de escrita. De acordo com Lorde (2020, p. 53), esses silêncios necessitam ser desnaturalizados e, para que isso ocorra, é preciso que mais mulheres passem a escrever. Lorde (2020, p. 53) ainda acredita que alguns dos principais fatores da dificuldade de mulheres escreverem são a insegurança, o medo do julgamento e a crença de que essa atividade é um luxo, isto é, para mulheres que tenham um teto todo delas como Virginia Woolf.

A fim de quebrar com a falsa impressão de "segurança", Lorde explica que "fomos socializadas a respeitar mais o medo do que nossas necessidades de linguagem e significação, e enquanto esperarmos em silêncio pelo luxo supremo do destemor, o peso desse silêncio nos sufocará" (LORDE, 2020, p. 55). De acordo com a poeta, mesmo que as mulheres 
não escrevessem, estas ainda sofreriam julgamentos, daí a necessidade de participar do processo de autodeterminação de sua própria escrita do que sofrer em silêncio. É interessante notar que as estratégias de supressão foram tão bem elaboradas que mesmo as mulheres como Lola Ridge, cuja obra chegou a ser publicada, passa a ser enterrada após a sua morte. Como, então, é possível combatê-las?

A pesquisa pelo viés da Crítica Feminista dentro da literatura é muito frutífera, pois possibilita questionamentos em relação aos arquétipos femininos e à condição da mulher como personagem ou como produtora de textos. No entanto, seria possivel desconstruir esses arquétipos, personagens e crenças tão naturalizadas acerca da mulher? Sobre isso, a Tradução Feminista possui um papel fundamental não apenas na divulgação de textos feministas ou de mulheres, mas na formulação de um discurso verdadeiramente feminista, isto é, além de recuperar as obras de autoras que foram silenciadas para traduzi-las e recomercializá-las, as estratégias usadas para o processo de tradução são pensadas na perspectiva do gênero, a fim de que não haja o reforço de arquétipos hegemônicos e patriarcais - da representação das mulheres.

Se, ao pensar o silêncio, de acordo com Orlandi (1997), a partir de uma perspectiva discursiva, infere-se que este 
significa em si, é necessário atentar-se ao fato de que o discurso é produzido dentro de relações de poder e que este silêncio também significa dentro dessas relações desiguais. Sendo assim, pode-se inferir que o cânone literário se torna cânone por atender às necessidades do discurso dominante e, se existe um discurso dominante, pressupõe-se a existência de discursos marginalizados. Ao recuperar e traduzir textos como os poemas de Lola Ridge, por exemplo, propõe-se, além do des-silenciamento desta autora, a recuperação de uma rede de outras autoras que foram também silenciadas.

De acordo com Collins (2019, p. 28), traduzir a partir da Tradução Feminista é criar novos conhecimentos, é um ativismo intelectual que necessita da confiança dos sujeitos envolvidos nesse processo, pois os tradutores podem servir como os mediadores de poder tanto em favor do discurso dominante canônico, quanto em favor de uma participação ativa na construção de um discurso contra-hegemônico. Portanto, o ato de traduzir pode ser entendido como uma forma de combater o silenciamento e ecoar a voz de autoras marginalizadas. É de extrema importância que, ao pensar os silêncios a partir da perspectiva discursiva, como proposto por Orlandi (1997), se pense também por uma perspectiva feminista, para que essas políticas de censura sejam 
desnaturalizadas e entendidas como estratégias políticas de manutenção do status quo de um cânone excludente.

\section{CONSIDERAÇÕES FINAIS}

Pensar as políticas do silêncio a partir da perspectiva discursiva, como proposto por Orlandi (1997), é compreender que o discurso é produzido dentro de relações de poder. Essas relações refletem, (re)produzem e reforçam uma determinada ordem social. Sendo assim, é interessante questionar o que os silêncios significam, pelo viés discursivo, dentro do cânone literário. Embora a deslegitimação da escrita de mulheres seja incontestável, por que algumas mulheres conseguiram alcançar o prestígio literário?

Se o discurso é produzido dentro de relações poder, logicamente existe uma hierarquia entre quem pode e quem não pode (ou não deve) falar. As escritoras que alcançaram seu espaço no cânone literário são, em sua grande maioria, mulheres burguesas que tinham condições materiais de produzirem seu trabalho, isto é, dispunham de tempo e instrumentos para isso e seus textos atendiam às expectativas da concepção de arte burguesa porque talvez não desafiassem demais a estética hegemônica canônica. No entanto, ainda assim, elas são questionadas sobre a qualidade de seu trabalho, são recategorizadas 
como escritoras confessionais, são entendidas como únicas - "exceções à regra", afinal, a regra era que mulher não deveria escrever -, são vistas como autoras de um livro só, e entre outras estratégias já descritas aqui. Se o discurso produzido pelas mulheres é tão perigoso que deve, a todo custo, ser posto à prova, deve ser porque essas mulheres possuem um poder transformador e desestabilizador em sua escrita.

Portanto, analisar o padrão estudado por Russ (2018) no silenciamento da escrita de mulheres é necessário, pois este ajuda a compreender os mecanismos e estratégias utilizadas por aqueles que querem manter o status quo do cânone literário para, por fim, combatê-las. A partir disso, surge a necessidade de buscar formas de combate para que as mulheres ocupem mais espaço e se tornem modelos para futuras mulheres. No entanto, é importante também recuperar o trabalho de mulheres que já trilharam esse caminho e tiveram suas vozes silenciadas e esquecidas. Neste ponto, a Tradução Feminista possui, como um de seus diversos objetivos, um trabalho paleontológico de pesquisa para desenterrar obras, como a poesia feminista e radical de Lola Ridge, que foram relegadas ao esquecimento ao longo do tempo e traduzi-las, a fim de reinseri-las na circulação de textos literários. 
Em suma, é a partir do entendimento de como funcionam as políticas do silêncio que será possível des-silenciar e recuperar as obras dessas autoras. Contudo, isso não é o bastante. É necessário compreender que esse silenciamento é imposto e, para além disso, questionar quais são as relações de poder que o cânone literário pretende manter. Propor uma reformulação canônica não é o suficiente, pois o cânone representa uma ordem social hegemônica e apenas ceder espaço para mulheres escritoras nele não altera essa ordem. Todavia, questioná-lo possibilita discussões fundamentais acerca do papel da arte na sociedade e torna-se um dos caminhos para a produção e destaque de obras de grupos que "deveriam ser silenciados", entre eles, as mulheres, a fim de que se construa discursos contrahegemônicos, como a obra poética feminista de Lola Ridge aqui citada, e muitas outras obras de mulheres feministas que foram enterradas no chão da história.

\section{REFERÊNCIAS}

BERKE, Nancy. Women Poets on the Left: Lola Ridge, Genevieve Taggard, Margaret Walker. Gainesville: University Press of Florida, 2001. COLLINS, Patricia Hill. Sobre tradução e ativismo intelectual. Ártemis Estudos de Gênero, Feminismos e Sexualidades, v. 27, n. 1, p. 25-32, 11 jul. 2019. Disponível em: https://periodicos.ufpb.br/index.php/artemis/ article/view/46697/27496. Acesso em: 25 de fev. de 2021. LORDE, Audre. A transformação do silêncio em linguagem e em ação. In: 
LORDE, Audre. Irmã Outsider: ensaios e conferências. Belo Horizonte: Autêntica, p. 51-55, 2020.

OLSEN, Tillie. Silences. New York: Feminist Press at the City University of New York, p. 321, 2003.

ORLANDI, Eni Puccinelli. As formas do silêncio: no movimento dos sentidos. Campinas, São Paulo: Editora da Unicamp, 1997.

RUSS, Joanna. How to supress women's writing. Austin, Tx, Estados Unidos: University Of Texas Press, p. 224, 2018.

Laura Pinhata Battistam

Mestranda (Programa de Pós-graduação da Universidade Estadual de Maringá - UEM).

Participa do grupo de pesquisa "Tradução \& Multidisciplinaridade: da Torre de Babel à sociedade tecnológica" (UEM).

http://lattes.cnpq.br/6201120247266812

https://orcid.org/0000-0003-3356-8041

laurabattistam74@gmail.com

Líliam Cristina Marins

Doutora em Letras pelo Programa de Pós-graduação em Letras da Universidade Estadual de Maringá (UEM).

Professora da graduação (UEM); professora no Programa de Pósgraduação (UEM).

Participa dos grupos de pesquisa "Projeto Nacional de Letramentos: Linguagem, Cultura, Educação e Tecnologia" (USP) e "Tradução e Multidisciplinaridade: da torre de Babel à sociedade tecnológica" (UEM). http://lattes.cnpq.br/7387068825282075 http://orcid.org/0000-0002-9954-4985 liliamchris@hotmail.com 